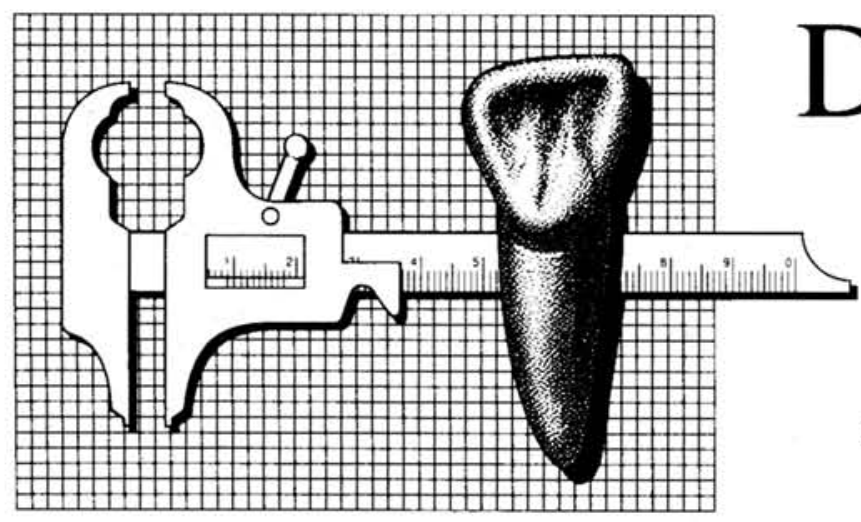

Dental Anthropology
Newsletter

A PUBLICATION OF

THE DENTAL ANTHROPOLOGY ASSOCIATION

Laboratory of Dental Anthropology Department of Anthropology

Arizona State University Tempe. AZ 85287-2402

Volume 7, Number 2

January, 1993

\title{
Periodontitis in Dry Skulls
}

\author{
NIGEL CLARKE \\ Department of Dentistry, The University of Adelaide GPO Box 495, Adelaide South Australia 5001
}

It has been widely thought that periodontitis is an ancient disease, affecting most members of all cultural groups (Schluger et al., 1977). This concept of periodontitis was supported by many early anthropological and epidemiological studies, but since the mid-eighties it has become evident that at the present time periodontitis is neither an all-embracing disease nor an important cause of tooth loss (Bouma et al., 1987; Bailit et al., 1987; Pilot et al., 1992). This paper considers some factors that have led to the controversy between those who believe that periodontitis is ubiquitous and damaging and those who think that it represents an unusual and minor problem.

\section{PERIODONTAL DISEASE (PERIODONTITIS): DEFINITION}

An early definition of periodontitis to adequately describe what might be measured in the dry skull and recorded as periodontitis was "...the surface of the alveolar crest appears porous at the interproximal septa and crenated along the facial and lingual limbi alveolares" (Ruffer, 1920). This definition requires modification as crenations (notching) of the margins appear to be a normal but not a universal feature of crestal bone. Notching appears to be relatively common in older subjects and may have some association with the physiological process of continuous tooth eruption.

The critically important feature of periodontitis is the exposure of cancellous bone, following the loss of the covering cortical plate of the alveolus, to give a porous appearance. Alveolar tissue damaged by periodontitis should also demonstrate the loss of the crestal knife-edged contour to result in a rounded alveolar margin. Alexandersen (1967) reviewed the criteria for the appropriate assessment of periodontitis in dry skulls and reinforced the opinions and observations of Ruffer. However, very few assessments of periodontitis in dry skulls since that time have adopted an objective assessment for the loss of alveolar bone. As a result, physiological and dental causes of alveolar bone loss have been confused with periodontitis.

\section{PHYSIOLOGICAL CAUSES OF PERIODONTAL ATTACHMENT LOSS}

In anthropological studies, periodontitis has usually been assessed by the examination of the relationship between the cemento-enamel junction (CEJ) of the tooth with the alveolar crest (AC) of the bone. It has been assumed that these anatomical markers represent fixed points in health throughout life. Increase in the distance between the two positions was deemed to represent loss of bone. However, some early workers were aware that the increasing CEJ-AC distance did not in itself represent disease. Leigh (1925) recorded alveoclasia only when the roots were exposed appreciably more than could be explained by a slow gradual recession of the alveolar crest with age and physiological eruption of the teeth. It is now clear that there is no evidence for recession of the alveolar bone with increasing age but there is a physiological continuous eruption of teeth. 


\section{MEASUREMENT OF PERIODONTITIS}

Two indices have been proposed and used to measure periodontitis, based solely upon CEJ-AC distances: the Tooth-Cervical Height Index (TCH) (Davies et al., 1969) and the Root Index (Goldberg et al., 1976). The major confounding factor associated with these indices is the physiological process of continuous tooth eruption. Teeth move progressively in a mesial and occlusal direction throughout life in compensation for real or anticipated occlusal attrition (Murphy, 1959). These physiological movements affect all teeth in all people but are probably governed by the usual variables associated with lifestyle, culture, and genes. If this physiological variable becomes incorporated into an index of disease, it is inevitable that the incidence of disease will be found to be very high (ubiquitous). It is now reasonable to conclude that data for periodontitis based upon CEJ-AC measurements have inevitably measured both the physiological effects of continuous tooth eruption (approximately $0.1 \mathrm{~mm}$ per year) as well as any loss of crestal bone if present.

Many authors noted that there was severe attrition in many cultural groups and noted that there was a correlation between the severity of tooth wear and increased CEJ-AC distances. To determine whether tooth or bone movement was responsible for increasing $\mathrm{CEJ}-\mathrm{AC}$ distance required a fixed reference point not associated with either marker.

The key breakthrough was made by Newman and Levers, (1979) who proposed that the inferior dental canal (IDC) of the mandible was a useful reference point from which the relative positions of the $\mathrm{AC}$ and the CEJ could be assessed. They found that the distance between the IDC and the alveolar crest was maintained or even slightly increased with advancing age indicating that there is no atrophy of crestal alveolar bone. The IDC-CEJ distance increased throughout life, indicating that relative to the IDC it was the tooth, not the bone that was unstable. Behrents (1985) found that teeth remain upright throughout life and several workers have observed that face height was maintained in the presence of severe wear by progressive continuous tooth eruption (Baarregaard, 1949; Murphy, 1959; Taylor, 1963; Barker, 1975). Many other workers have confirmed the physiological status of continuous tooth eruption (Clarke and Hirsch, 1991).

\section{PATHOLOGICAL CAUSES OF ALVEOLAR BONE LOSS}

\section{Generalized periodontitis}

An assessment of alveolar bone using an approach consistent with the concepts of Ruffer and Leigh in a diverse collection of skeletal materials, led to the conclusion that generalized horizontal periodontitis was unusual in dry skulls (Clarke et al., 1986). Furthermore, these findings confirm the evidence presented by a diverse group of researchers (Leigh, 1925; Pedersen, 1946; Phillipas, 1952; Greene et al., 1966; Newman and Levers, 1979; Costa, 1982; Whittaker et al., 1985; Clarke et al., 1986). This view of periodontitis is not universally accepted; recently it has been stated "...periodontal disease has remained a major oral health problem and has replaced caries as the leading cause of adult tooth loss" (Hildebolt and Molnar, 1991).

Although generalized horizontal periodontitis has been accepted as an ancient disease affecting most members of all cultural groups, there appears to be inadequate evidence to support such a conclusion. The opinions supporting a high incidence of generalized horizontal periodontitis in dry skulls are not founded upon a rational analysis of crestal bone.

\section{Localized periodontitis}

The localized form of periodontal disease has been variously referred to as alveoclasia, suppurative, retrograde and complex periodontitis. Extensive study of many skulls from diverse cultures reveals that localized periodontitis strongly correlates with perforation of the dental pulp by caries or severe attrition. It may be reasonably inferred that caries and severe occlusal wear resulting in perforation admit oral bacteria to the tooth pulp. Host defenses attempt to maintain the integrity of the tissue but the inflammatory consequences of the resulting conflict between parasite and host has the potential to impact upon the external supporting structures of the tooth. There is no reasonable doubt that the dental pulp does induce lesions in both the coronal and all other areas of the periodontium, but the critical 
question is whether inflammation of the gingiva has the capacity to induce similar lesions. It is most unusual for two different pathoses to have an identical physical effect.

Early caries results in a relatively low level of bacterial penetration into the tissues, providing for a long conflict between the host and parasite in the coronal aspect of the tissue. These conditions may be apt to induce changes in the adjacent periodontal tissues at or adjacent to the crest. These defects can result in total loss of bone on the buccal and lingual aspects of the teeth and infra bony pockets within the proximal (mesial and distal) surfaces. The third region affected is within the root forks of multi-rooted teeth which may induce furcation defects. These alveolar changes have typically been described as periodontal but they are the first phase of dental disease affecting the periodontium.

Localized damage to the periodontium is not limited to teeth with caries or perforated crowns (Pedersen, 1938; Koritzer, 1968; Clarke, 1990). An intact external surface of a crown does not mean that the internal tissues are of necessity healthy. It is not possible to clinically demonstrate the subtle pathways available for bacteria to gain entry to the pulp in a sound crown, but pathways exist where there is insufficient cementum, or micro-cracks. Teeth with sound crowns are seen where a classical apical dental abscess has developed, demonstrating the potential of an apparently sound tooth to develop dental disease (phase 2 changes of dentally induced changes in the periodontium). There is no doubt that alveolar bone changes can be associated with pulpal disease in an intact tooth crown.

The compelling implications are that localized periodontitis is a disease of the periodontium of dental origin. In addition, there is no evidence that the presence of bacteria in the gingival crevice can induce localized periodontitis. The bacterial flora is not limited to diseased sites, and the bacteria suggested to have the potential to induce alveolar disease have not been able to do so when inoculated (Christersson et al., 1985). Bacteria are fastidious and colonize sites that provide the conditions for their support; they do not have the capacity to create sites that they require.

There is no anthropological evidence that localized periodontal damage occurs from the coronal gingival tissue; the morphological evidence points to a dental cause. The third phase of abscess development occurs when defects arising more deeply within the periodontium track along cancellous pathways of proximal tissue to merge with defects induced earlier in the process or independently forge their way to the alveolar crest (Clarke, 1992). In this way both early and late consequences of dental abscess formation impact upon the alveolar crest.

\section{EVALUATION OF ALVEOLAR BONE CHANGES}

When attempting to estimate the presence or absence of generalized periodontitis in dry skulls it would seem imperative that:

1. An attempt be made to establish whether there are physical changes in the crestal bone that are consistent with the erosion of the surface to leave a cancellous (porous) structure and modified contour.

2. A computation should be made for continuous tooth eruption based upon an eruptive rate of approximately $0.1 \mathrm{~mm}$ per year. Tooth eruption as a consequence of both increasing age and compensation for attrition should be expected. Increasing CEJ-AC distances do not alone constitute a disease. Continuous tooth eruption is more readily detected in the dry skull than in clinical observation but the process has been confirmed in the living (Ainamo and Talari, 1976).

3. It is now 70 years since Hirschfeld (1923) recognized the potential of the dry skull to provide evidence for the pathogenesis of periodontal disease. However, since that time, concepts have become entrenched in anthropological and clinical practice that cannot be substantiated from studies of the dry skull. Perhaps it is an opportune time to again focus attention on dry skulls to realize the potential that they hold in unravelling the web of conflicting opinions relating to the incidence and origins of alveolar bone loss.

\section{CONCLUSIONS}

Generalized periodontitis is of minimal presence and minimal consequence in anthropological materials; it is not responsible for tooth loss but requires differentiation from physiological attachment loss. Tooth morbidity and mortality occur as a result of localized bone loss of dental origin. 


\section{PERIODONTITIS IN DRY SKULLS}

\section{LITERATURE CITED}

Ainamo J, and Talari A (1976) The increase with age of the width of attached gingiva. J. Perio. Res. 11:182-188.

Alexandersen V (1967) The pathology of the jaws and the temporomandibular joint. In D Brothwell and AT Sandison (eds.) Diseases in Antiquity: A Survey of the Diseases, Injuries and Surgery of Early Populations. Springfield, Illinois: Charles C. Thomas, pp. 551-595.

Baarregaard A (1949) Dental conditions and nutrition among natives in Greenland. Oral Surg. Oral Med. Oral Path. 2:995-1007.

Bailit HL, Braun R, Marynuik GA, and Camp P (1987) Is periodontal disease the primary cause of tooth extraction in adults? J. Am. Dent. Assn. 114:40-45.

Barker BCW (1975) Relation of the alveolus to the cemento-enamel junction following attritional wear in aboriginal skulls. An enquiry into the normality of cementum exposure with aging. J. Periodontol. 46:357-363.

Behrents RG (1985) Growth in the Aging Craniofacial Skeleton. Ann Arbor: The University of Michigan, pp. 69-126.

Bouma J, Schaub RMH, and Van De Poel ACM (1987) Relative importance of periodontal disease for full mouth extractions in the Netherlands. Community Dent. Oral Epidemiol. 15:41-45.

Clarke NG (1990) Periodontal defects of pulpal origin: evidence in early man. Am. J. Phys. Anthropol. $82: 371-376$.

Clarke NG (1992) Some anatomical factors that influence the pathways followed by dental inflammatory exudates. In T Brown and S Molnar (eds.): Craniofacial Variation in Pacific Populations. Adelaide, Department of Dentistry, The University of Adelaide, pp. 129-137.

Clarke NG, and Hirsch RS (1991) Physiological, pulpal and periodontal factors influencing alveolar bone. In MA Kelley and CS Larsen (eds): Advances in Dental Anthropology. New York: Wiley-Liss, pp. 241-266.

Clarke NG, Carey SE, Srikandi W, Hirsch RS, and Leppard P (1986) Periodontal disease in ancient populations. Am. J. Phys. Anthropol. 71:173-183.

Christersson LA, Slots J, Zambon JJ, and Genco RJ (1985) Transmission and colonization of Actinobacillus actinomycetemcomitans in localized juvenile periodontitis patients. J. Periodontol. 56:127-131.

Costa RL (1982) Periodontal disease in the prehistoric Ipiutak and Tigara skeletal remains from Point Hope, Alaska. Am. J. Phys. Anthropol. 59:97-110.

Davies DM, Picton DCA, and Alexander GA (1969) An objective method of assessing the periodontal condition in human skulls. J. Periodont. Res. 4:74-77.

Goldberg HJV, Weintraub JA, Roghmann KJ, and Cornwell WS (1976) Measuring periodontal disease in ancient populations: root and wear indices in study of American Indian skulls. J. Periodontol. 47:348-351.

Greene DL, Ewing GH, and Armelagos GJ (1966) Dentition of a mesolithic population from Wadi Halfa, Sudan. Am. J. Phys. Anthropol. 27:41-56.

Hildebolt CF, and Molnar S (1991) Measurement and description of periodontal disease in anthropological studies. In MA Kelly and CS Larsen (eds.) Advances in Dental Anthropology. New York: Wiley-Liss, pp. 225-240.

Hirschfeld I (1923) A study of skulls in the American Museum of natural history in relation to periodontal disease. J. Dent. Res. 5:241-265.

Koritzer RT (1968) Periapical lesions without apparent route of infection. J. Dent. Res. 47:840.

Leigh RW (1925) Dental pathology of Indian tribes of varied environmental and food conditions. Am. J. Phys. Anthropol. 8:179-199.

Murphy T (1959) Compensatory mechanisms in facial height adjustment to functional tooth attrition. Aust. Dent. J. 4:312-323.

Newman HN, and Levers BGH (1979): Tooth eruption and function in an early Anglo-Saxon population. Proc. Roy. Soc. Med. 72:341-350.

Pedersen PO (1938) Investigations into dental conditions of about 3,000 ancient and modern Greenlanders. The Dental Record 58:191-198.

Pedersen PO (1946) Dental investigations of Greenland Eskimos. Proc. Roy. Soc. Med. 40:726-732.

Phillipas GG (1952) Effects of function on healthy teeth: the evidence of ancient Athenian remains. J. Am. Dent. Assn. 45:443-453.

Pilot T, Miyazaki H, Leclerck M-H, and Barmes DE (1992) Profiles of periodontal conditions in older age cohorts, measured by CPITN. Int. Dent. J. 42:23-30.

Ruffer A (1920) Study of abnormalities and pathology of ancient Egyptian teeth. Am. J. Phys. Anthropol. 3:335-382.

Schluger S, Yuodelis RA, and Page RC (1977) Periodontal Disease. (1 ed.) Philadelphia: Lea and Febiger, p. 1.

Taylor RMS (1963) Cause and effect of wear of teeth. Acta Anatomica 53:97-157.

Whittaker DK, Molleson T, Daniel AT, Williams JT, Rose P, and Resteghini R (1985) Quantitative assessment of tooth wear, alveolar crest height and continuing eruption in a Romano-British population. Arch. Oral Biol. 30:493-501. 